\title{
PHOTOCATALYTIC TREATMENT OF TEXTILE DYEHOUSE EFFLUENTS WITH SIMULATED AND NATURAL SOLAR LIGHT
}

\author{
E. CHATZISYMEON \\ C. PETROU \\ D. MANTZAVINOS*
}

\author{
Department of Environmental Engineering \\ Technical University of Crete \\ GR-73100 Chania, Greece
}

Received: 07/04/12

Accepted: $16 / 11 / 12$ *to whom all correspondence should be addressed: e-mail: mantzavi@mred.tuc.gr

\section{ABSTRACT}

In the present study, the photocatalytic treatment of two synthetic textile dyehouse effluents was investigated. The first synthetic effluent (SE1) is a Remazol Black B aqueous solution, while the second one (SE2) is an aqueous mixture of sixteen dyes and auxiliary chemicals that are usually employed in the textile industry. Various illumination sources were studied, while emphasis was given on the use of simulated and natural solar light.

Results indicated that the use of solar irradiation can constitute an advantageous treatment strategy, due to its energy efficient and environmentally friendly operation, for textile dyehouse effluents. Specifically, it was observed that total decolorization and mineralization of SE1 occurred after about $120 \mathrm{~min}$ and $300 \mathrm{~min}$, respectively, in the presence of at least $2 \mathrm{~g} \mathrm{~L}^{-1} \mathrm{TiO}_{2}$, under natural sunlight. On the other hand, total decolorization of SE2 was achieved only after $300 \mathrm{~min}$ of photocatalytic treatment, while COD removal practically remained unchanged, at about $20 \%$, regardless the applied operating parameters, due to the presence of other organic and inorganic substances. Furthermore, it was found that process efficiency was significantly affected by the catalyst loading.

KEYWORDS: azo-dyes, photocatalysis, solar irradiation, textile wastewaters.

\section{INTRODUCTION}

Color is one of the most obvious indicators of water pollution and the discharge of highly colored effluents containing dyes can be damaging to the receiving bodies (Saltabas et al., 2012; Sousa et al., 2012). Dyes concentration in wastewaters is usually lower than any other chemical found in these wastewaters, but due to their strong color they are visible even at very low concentrations, thus causing serious aesthetic and pollution problems in wastewater disposal. Furthermore, dyes represent about $50 \%$ of the worldwide production and correspond to an important source of contamination considering that approximately $15 \%$ of the synthetic textile dyes are lost in waste streams during manufacturing or processing (Silva and Faria, 2003). Among the various dye molecules, azo-dyes are of great concern because of their widespread use especially in the textile industry, the likely formation of toxic aromatic amine intermediates under anoxic conditions, and recalcitrance to aerobic wastewater treatment (Wang et al., 2008; Aber and Haddadi Esfahlan, 2011).

Therefore, methods for decolorization of textile wastewaters have received considerable attention in recent years. Among them, $\mathrm{TiO}_{2}$ photocatalysis is an advanced oxidation process with key advantages, over other water treatment technologies, including the lack of mass transfer limitations, operation at ambient conditions and the potential use of solar radiation (i.e. a cheap, abundant and clean source of energy) (Chan et al., 2011). So far, there have been a relatively large number of papers dealing with the photocatalytic degradation of model dyes, such as Remazol Black B (i.e. an azo-dye widely used in textile manufacturing) in the presence 
of ultraviolet (UV) or solar radiation (Li and Zhang, 1996; Poulios and Tsachpinis, 1999; Silva and Faria, 2003; Muruganandham et al., 2006; Khataee et al., 2010; Soutsas et al., 2010; Gümüş and Akbal, 2011). However, there are appreciably fewer reports regarding the $\mathrm{TiO}_{2}$ photocatalytic degradation of actual or simulated dyes effluents under solar radiation (Pekakis et al., 2006; Orozco et al., 2009; Rupa et al., 2011).

Therefore, in this work the photocatalytic degradation of two different synthetic textile dyehouse effluents, namely (i) a model aqueous solution of Remazol Black B (SE1), and (ii) an aqueous mixture of sixteen dyes (SE2) typically used in the textile industry, is investigated. The effect of various operating parameters such as radiation source, catalyst concentration and the type of the effluent on process efficiency is studied. Emphasis is given on the photocatalytic degradation of textile effluents under simulated or natural solar radiation.

\section{MATERIALS AND METHODS}

SE1 was prepared dissolving Remazol Black B (RBB) in distilled water at a concentration of $159 \mathrm{mg}$ $\mathrm{L}^{-1}$. SE2, a mixture of sixteen dyes and auxiliary chemicals, simulates a real effluent emanating from the textile dyeing process as described in detail elsewhere (Chatzisymeon et al., 2006). The dyeing recipe, as well as the various dyes were kindly provided by a textile manufacturing industry (Epilektos SA, located in the region of Sterea, Central Greece). RBB is the main dyeing compound in SE2, whose composition is shown in Table 1.

The catalyst used in this study was a commercially available Aeroxide P25 (formerly known as Degussa P25) $\mathrm{TiO}_{2}$ powder (Evonik Industries AG), which is a mixture of 75:25 anatase:rutile at $50 \pm 15 \mathrm{~m}^{2} \mathrm{~g}^{-1}$ specific surface area and $21 \mathrm{~nm}$ primary particle size. Irrespective of the type of illumination source, the appropriate amount of catalyst was slurried in the reactor under continuous stirring.

Photocatalytic experiments under UVA radiation were conducted in batch type, laboratory-scale photoreactors described in detail elsewhere (Pekakis et al., 2006). Radiation was provided by (i) a 9 W Radium Ralutec 78 UVA G23 lamp, or (ii) a $400 \mathrm{~W}$ high pressure mercury lamp (Osram, HQL, MBF-U). The photon flux emitted by the UVA lamps was determined by chemical actinometry using potassium ferrioxalate and found to be $4.69 \times 10^{-6}$ and $1.12 \times 10^{-5}$ einstein $\mathrm{s}^{-1}$ for the 9 and $400 \mathrm{~W}$ lamps, respectively. Furthermore, experiments under simulated solar radiation (provided by a Newport 67005 - $150 \mathrm{~W}$ solar simulator system) were performed in an open cylindrical pyrex cell at ambient conditions (see Frontistis et al. (2011) for a similar set-up). Chemical actinometry based on 2-nitrobenzaldehyde photoreaction was performed to measure the photon flux emitted from the solar simulator system which was found equal to $9 \times 10^{-5}$ and $2.7 \times 10^{-5}$ einstein $\mathrm{s}^{-1}$, when the effluent volume was $160 \mathrm{~mL}$ and $300 \mathrm{~mL}$, respectively.

Photocatalytic experiments under natural sunlight were carried out in a batch-type, laboratory-scale photoreactor. This was tightly fastened with a glass cover to minimize evaporation due to heating. All sunlight experiments were performed under similar conditions on sunny days of June, between 11:00 and 16:00 hours, when the intensity of the sun is at its maximum. The average intensity of natural solar light during the study period was found to be $1.36 \times 10^{-4}$ einstein $\mathrm{s}^{-1}$.

COD was determined by standard methods using commercially available digestion solution kits (0$150 \mathrm{mg} \mathrm{L}^{-1}$, Hach Europe, Belgium). Color was measured on a Shimadzu UV 1240 spectrophotometer at $\lambda=598 \mathrm{~nm}$, which corresponds to the maximum absorbance in the visible region.

\section{RESULTS AND DISCUSSION}

\subsection{Effect of the radiation source}

Different illumination sources were used in order to investigate whether the type of radiation affects photocatalytic efficiency. As can be observed in Figure 1, despite the fact that the UVA $(400 \mathrm{~W})$ and the simulated solar lamps bear about the same photon flux (i.e. in the order of $10^{-5}$ einstein $\mathrm{s}^{-1}$ ), photocatalytic performance is sufficiently higher in the presence of UVA radiation. This is due to the fact that $\mathrm{TiO}_{2}$ can be activated at wavelengths below about $385 \mathrm{~nm}$, i.e. in the UV region of the electromagnetic spectrum. Solar radiation consists of only about $5 \%$ of UVA radiation, while the rest illuminates in the visible region of the electromagnetic spectrum. 
Table 1. Composition of the effluents used in this study

\begin{tabular}{lcccc}
\hline \multicolumn{1}{c}{ Component } & $\begin{array}{c}\text { SE1; Dye } \\
\text { concentration, } \\
\text { mg L-1 }^{-1}\end{array}$ & $\begin{array}{c}\text { SE1; Dye } \\
\text { percentage in } \\
\text { the effluent, } \%\end{array}$ & $\begin{array}{c}\text { SE2; Dye } \\
\text { concentration, } \\
\text { mg L-1 }^{-1}\end{array}$ & $\begin{array}{c}\text { SE2; Dye } \\
\text { percentage in } \\
\text { the effluent, \% }\end{array}$ \\
\hline Remazol Black B & 159 & 100 & 159 & 44 \\
\hline Remazol Red RB & - & - & 37.3 & 10.3 \\
\hline Remazol Golden Yellow RNL & - & - & 20.3 & 5.6 \\
\hline Cibacron Black WNN & - & - & 94.2 & 26.1 \\
\hline Cibacron Red FN-R & - & - & 0.1 & $<0.1$ \\
\hline Cibacron Blue FN-G & - & - & 0.6 & $<0.1$ \\
\hline Drimaren Red K-8B & - & - & 6.7 & 1.9 \\
\hline Drimaren Scarlet K-2G & - & - & 9.4 & 2.6 \\
\hline Drimaren Yellow K-2R & - & - & 12.1 & 3.3 \\
\hline Drimaren Navy K-BNN & - & - & 5.6 & 1.6 \\
\hline Drimaren Yellow K-4G & - & - & 12 & 3.3 \\
\hline Drimaren Orange X-3LG & - & - & 0.1 & $<0.1$ \\
\hline Drimaren Blue X-3LR & - & - & 0.05 & $<0.1$ \\
\hline Drimaren Violet K-2RL & - & - & 0.3 & $<0.1$ \\
\hline Drimaren Red K-4BL & - & - & 0.4 & 0.1 \\
\hline Drimaren Blue K-2RL & - & - & 2.6 & 0.7 \\
\hline Total dye content & - & - & 360.8 & 100 \\
\hline $\mathrm{Na}_{2} \mathrm{SO}_{4}$ & - & - & 5500 & - \\
\hline $\mathrm{Na}_{2} \mathrm{CO}_{3}$ & - & - & 440 & - \\
\hline $\mathrm{NaOH}^{\mathrm{COD}}$ & - & - & 110 & - \\
\hline
\end{tabular}

Therefore, when photochemical oxidation of the effluent is carried out in the presence of UVA radiation, all photon flux diffused in the aqueous solution is absorbed by the $\mathrm{TiO}_{2}$. Besides, when radiation is provided by the solar illumination source, only a small part of the emitted photon flux seems to promote photochemical oxidation onto the $\mathrm{TiO}_{2}$ surface.

Treatment of SE2 with the UVA $(400 \mathrm{~W})$ lamp results in complete decolorization and mineralization after 30 and 60 min of reaction, respectively. On the other hand, the use of UVA $(9 \mathrm{~W})$ lamp does not provide enough photonic energy to induce sufficient decolorization (i.e. only $40 \%$ after $180 \mathrm{~min}$ ) and/or mineralization (i.e. only about $10 \%$ after $180 \mathrm{~min}$ ); this is consistent with the fact that the photon flux of the $400 \mathrm{~W}$ lamp is an order of magnitude greater than that of the $9 \mathrm{~W}$ lamp.

To develop a photocatalytic process for textile wastewater treatment, further research should focus on the most energy- and, thus, cost-effective strategy. In this perspective, subsequent experiments were performed by means of solar radiation to investigate whether textile effluents can be substantially degraded using a highly efficient photocatalytic process from both an environmental and economic point of view

(a)

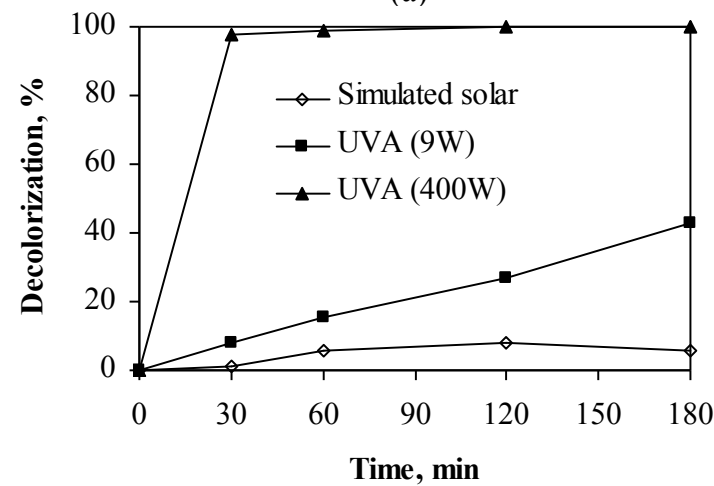

(b)

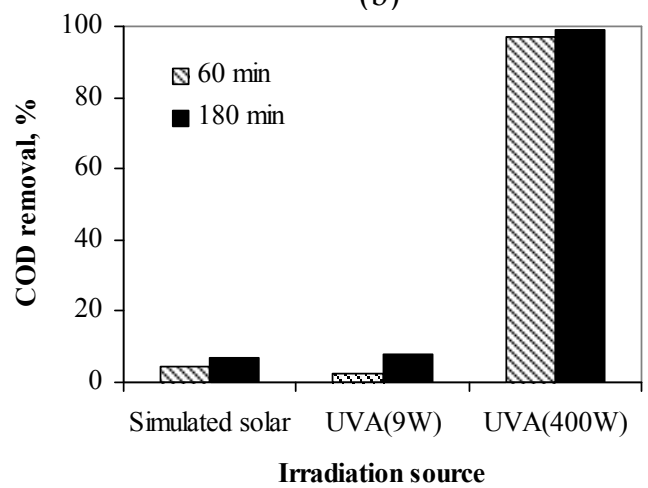

Figure 1. Effect of radiation source on the photocatalytic treatment of SE2 in the presence of $2 \mathrm{~g} \mathrm{~L}^{-1}$ $\mathrm{TiO}_{2}$. (a) Decolorization; (b) COD removal. Effluent volume is $300 \mathrm{~mL}$. 


\subsection{Effect of catalyst concentration}

Figure 2 shows that increasing catalyst concentration in the range $0.5-4 \mathrm{~g} \mathrm{~L}^{-1}$ generally enhances the decolorization and mineralization of SE1 and SE2. This is due to the fact that more active sites on the photocatalyst surface are available for reactions at higher concentrations, thus increasing the number of $\cdot \mathrm{OH}$ radicals that can take part in the oxidation of organics of the textile effluents (Rauf and Salman, 2009).

Regarding color removal for either SE1 or SE2 (i.e. Figures 2a and 2c, respectively), the beneficial effect of increasing catalyst concentration fades out at about $1-2 \mathrm{~g} \mathrm{~L}^{-1}$, since a further increase does not contribute significantly to decolorization. For example, an increase from 1 to $2 \mathrm{~g} \mathrm{~L}^{-1}$ of $\mathrm{TiO}_{2}$ increases SE1 decolorization from $53 \%$ to $77 \%$ after $300 \mathrm{~min}$, while in the presence of $4 \mathrm{~g} \mathrm{~L}^{-1} \mathrm{TiO}_{2}$, decolorization becomes $84 \%$. These results indicate that photocatalytic efficiency reaches a plateau regarding the catalyst loading and tends to remain stable upon further concentration increase, which is in agreement with a number of other studies (Konstantinou and Albanis, 2004; Muruganandham et al., 2006; Pekakis et al., 2006). This is probably due to the aggregation of a high concentration of catalyst, which could eventually reduce the total active surface area available for adsorbing dye molecules and solar radiation. Moreover, high concentration of catalyst creates turbidity, thus reducing the penetration ability of radiation due to scattering effects.

At the conditions in question, the optimum catalyst concentration for the complex textile effluent SE2, which is similar to real effluents, can be estimated at $1 \mathrm{~g} \mathrm{~L}^{-1}$. Figure $2 \mathrm{c}$ shows that this is the minimum amount of catalyst that can yield a substantial decolorization of about $40 \%$. Azo-dyes, such as $\mathrm{RBB}$, are characterized by $\mathrm{N}=\mathrm{N}$ double bonds that are usually attached to two radicals of which at least one but usually both are aromatic groups (benzene or naphthalene rings). The color of azodyes is determined by the azo bonds and their associated chromophores and auxochromes. Azo bonds are the most active bonds in azo-dye molecules and can be oxidized by the photogenerated holes and/or hydroxyl radicals or reduced by electrons in the conduction band and this cleavage of $\mathrm{N}=\mathrm{N}$ bonds leads to the decolorization of dyes. Figure 2 clearly shows that decolorization is always greater than COD removal and this is more pronounced for SE1, where color removal exhibits a twofold higher performance than mineralization. What happens is that $\mathrm{N}=\mathrm{N}$ double bonds are readily broken down and this is accompanied by the formation of more stable transformation by-products. This is consistent with the degradation mechanism of an azo-dye described in detail by Rauf and Salman (2009), where it is demonstrated that the cleavage of the double azo bonds occurs before any further degradation of the dye molecule.

This is also consistent with Figure 3, where SE1 (i.e. RBB) absorbance spectra before and after 300 min of photocatalytic treatment with various catalyst loadings, under simulated solar radiation, are shown. The two peaks at 598 and $310 \mathrm{~nm}$ correspond to the chromophore structure and naphthalene ring structure of RBB, respectively. The peak at $598 \mathrm{~nm}$ consistently decreases increasing catalyst loading and it is almost completely removed in the presence of $4 \mathrm{~g} \mathrm{~L}^{-1} \mathrm{TiO}_{2}$. On the other hand, the absorbance peak at $310 \mathrm{~nm}$ has been obviously declined increasing catalyst loading although its decrease is not as high as the decline of peak at $598 \mathrm{~nm}$. These results clearly indicate that the entire conjugated chromophore structure of RBB has been nearly completely destroyed achieving $84 \%$ decolorization (data also shown in Figure 2a). Furthermore, photocatalytic oxidation cannot effectively degrade the naphthalene ring compounds of RBB that correspond to the absorbance peak at $310 \mathrm{~nm}$, which is also consistent with the low rates of COD removal (Figure 2b).

\subsection{Can natural sunlight promote dyes photodegradation?}

Solar radiation is a free and abundant source of energy especially for countries around the Mediterranean basin, like Greece, where sunlight outlasts for many hours of the day and mostly between April and September, when its light intensity is at high level. This suggests that natural sunlight could be used as a radiation source for photocatalytic applications managing a more cost effective and environmentally friendly (as there are no energy wastes or process by-products) way to treat industrial wastewaters, such as textile effluents. 
(a)

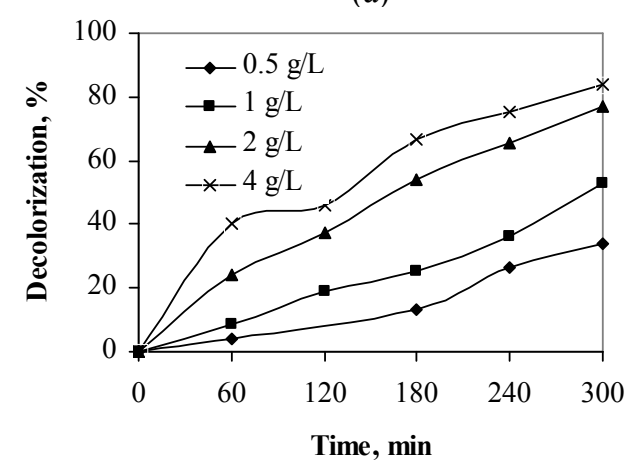

(c)

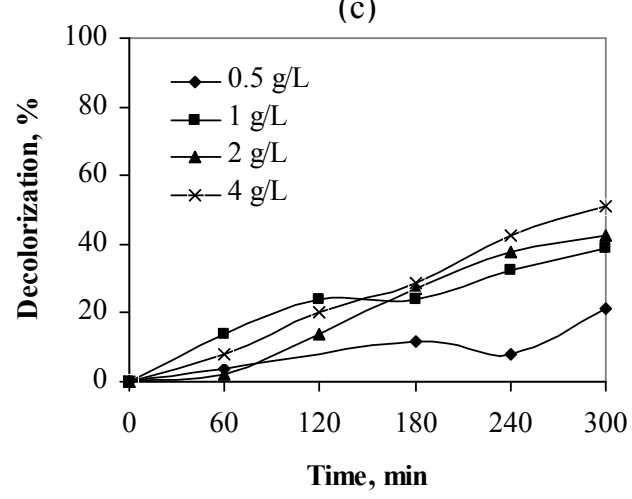

(b)

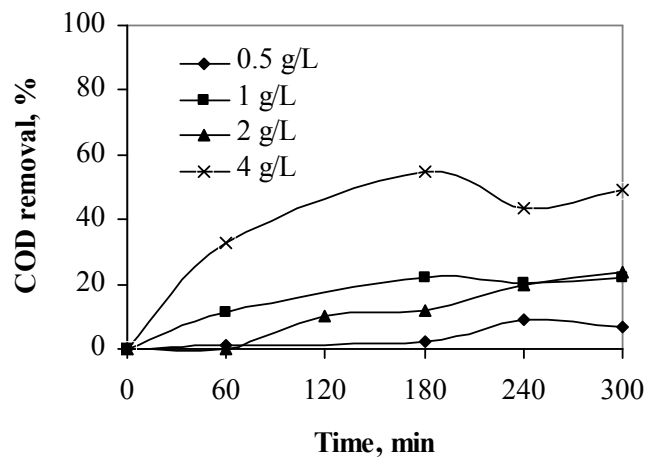

(d)

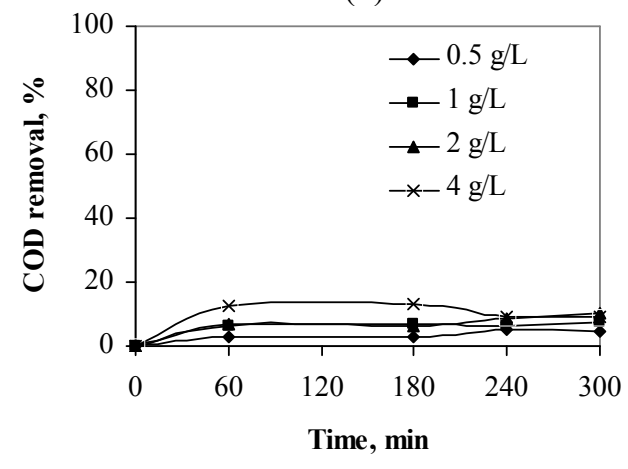

Figure 2. Photocatalytic treatment with simulated solar radiation and various $\mathrm{TiO}_{2}$ loadings.

(a) Decolorization of SE1; (b) COD removal of SE1; (c) Decolorization of SE2; (d) COD removal of SE2. Effluent volume is $160 \mathrm{~mL}$

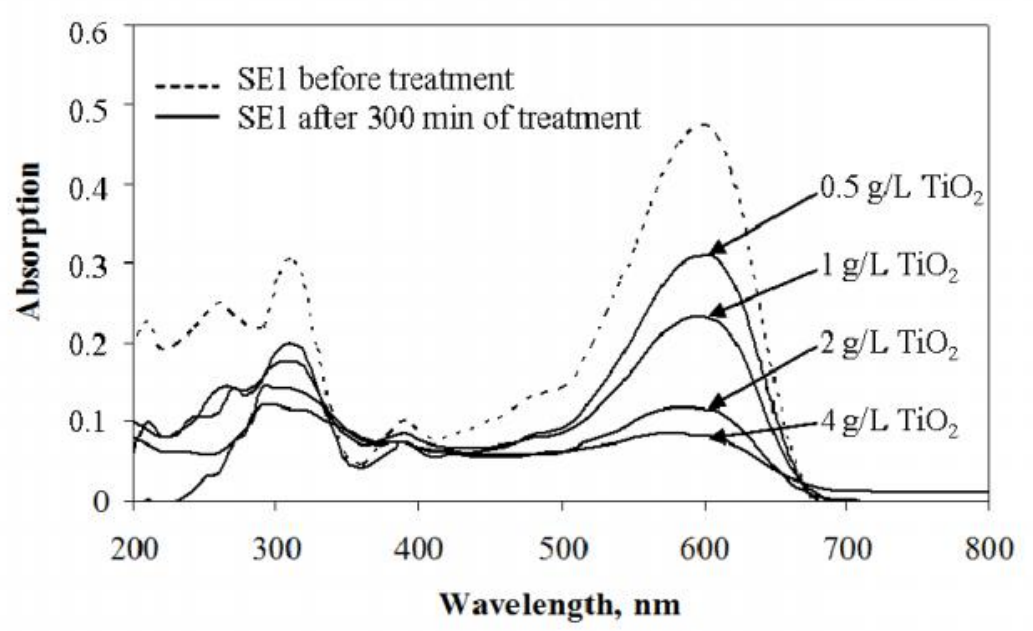

Figure 3. UV-visible absorbance spectra of SE1 before and after $300 \mathrm{~min}$ of photocatalytic treatment under simulated solar radiation and various catalyst loadings. Effluent volume is $160 \mathrm{~mL}$

Hence, experiments were conducted in order to investigate whether natural sunlight can efficiently oxidize textile dyehouse effluents. Each series of experiments were performed in parallel working photocatalytic reactors to ensure identical radiation conditions. Figure 4 shows the extent of COD and color removal during the photocatalytic treatment of SE1 and SE2 at various catalyst loadings. It is evident that an increase in the catalyst concentration brings about an increase in decolorization and COD removal for both SE1 and SE2. More specifically, complete SE1 decolorization and 
mineralization can be achieved after about 120 and $300 \mathrm{~min}$, respectively, in the presence of at least $2 \mathrm{~g} \mathrm{~L}^{-1} \mathrm{TiO}_{2}$. On the other hand, nearly complete SE2 decolorization occurs only after 300 min of photocatalytic treatment at $4 \mathrm{~g} \mathrm{~L}^{-1} \mathrm{TiO}_{2}$. As far as the COD removal is concerned (Figure 4d), this practically remains unchanged, at about $20 \%$, regardless the applied catalyst concentration. Direct photolysis (i.e. without catalyst) of the effluents was also tested yielding low color and COD removal; this confirms that degradation is predominantly due to the interaction between photonic energy and the catalyst surface rather than photolysis and/or photooxidation.

It is also noticeable that SE2 is more recalcitrant to photocatalytic treatment than SE1 and this is more pronounced in terms of mineralization rather than decolorization. A possible explanation would involve the complexity of the two effluents since (i) SE1 is a model aqueous solution of RBB alone, (ii) SE2 contains several other dyes and its total organic content is as much as about three times greater than SE1 (see Table 1), and (iii) SE2 also contains considerable amounts of salts and alkalis that may impede degradation.

(a)

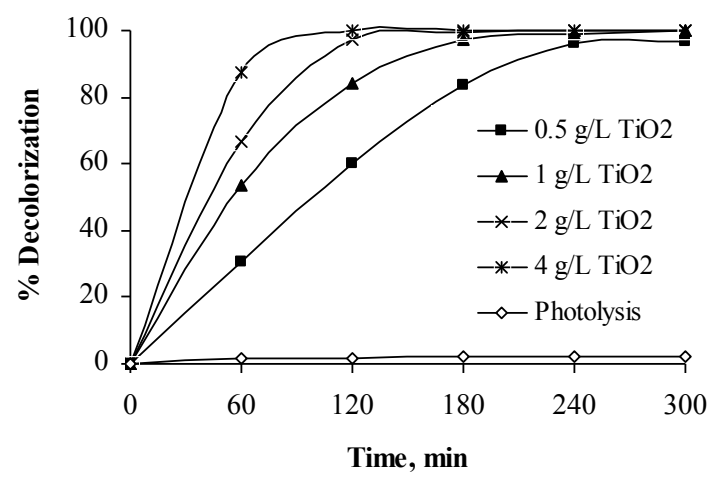

(c)

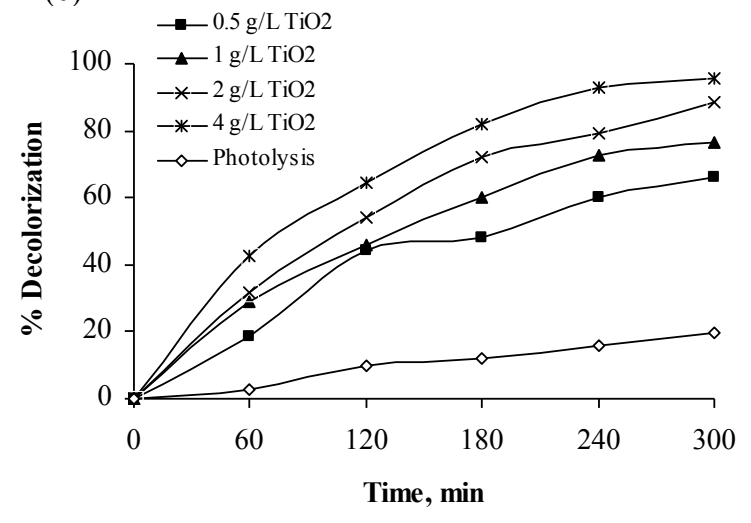

(b)

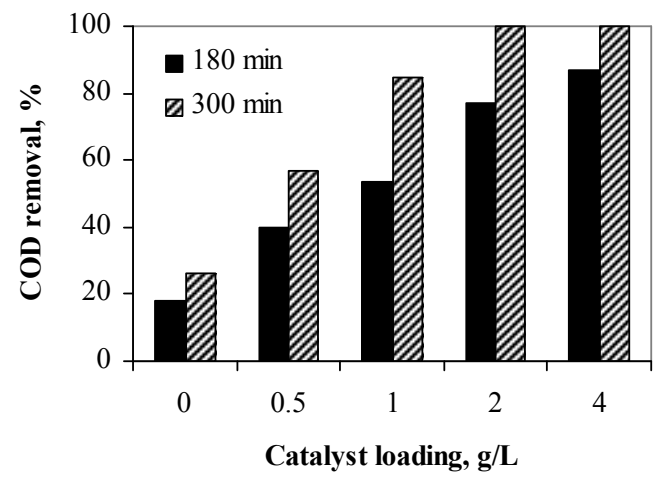

(d)

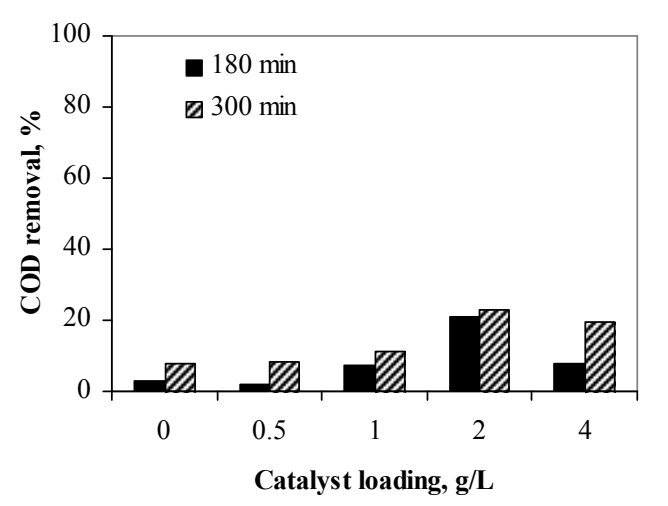

Figure 4. Photocatalytic treatment with natural sunlight and various $\mathrm{TiO}_{2}$ loadings. (a) Decolorization of SE1; (b) COD removal of SE1; (c) Decolorization of SE2; (d) COD removal of SE2. Effluent volume is $160 \mathrm{~mL}$

Working at identical conditions of photon flux and catalyst loading, the generation rate of oxidizing species (i.e. holes and radicals) would expectedly be the same. Although SE1 and SE2 contain exactly the same concentration of RBB, the latter also contains fifteen extra dyes at a cumulative concentration slightly higher than that of RBB; part of the non-selective oxidizing species will attack dyes other than RBB in SE2 and this explains its different reactivity from SE1. Furthermore, radicals may partly be scavenged by sulphates and carbonates in SE2 (Poulios and Kyriacou, 2002) and this would also decrease reactivity.

Notably, treatment performance under natural sunlight is generally greater than that under artificial solar radiation (comparison between Figures 2 and 4); this may be due to the slightly higher photon flux of natural light (ca $50 \%$ ), as well as to differences in reactor configurations that may affect light penetration. 


\section{CONCLUSIONS}

In this study, $\mathrm{TiO}_{2}$-mediated photocatalytic oxidation was applied to treat synthetic effluents coming from the textile industry. Emphasis was given on the degradation of these effluents under solar radiation. It was observed that process efficiency increased significantly increasing the amount of catalyst up to a value, above which further increase in $\mathrm{TiO}_{2}$ amount brought about the same photocatalytic yield. Moreover, it was found that the extent of decolorization was always higher than COD removal, indicating that chromophores are more susceptible to photocatalytic oxidation than its organic transformation by-products. The photocatalytic performance is strongly related to the type of the effluent since COD and color removal rates substantially decrease increasing effluent complexity (i.e. in terms of composition and concentration). Overall, the present results clearly indicate that the use of natural sunlight can offer a promising treatment strategy, due to its energy efficient and environmentally friendly operation, for textile dyehouse effluents.

\section{REFERENCES}

Aber S. and Haddadi Esfahlan F. (2011), Removal of C.I. Basic Yellow 2 from aqueous solution by adsorption onto granular activated carbon using an on-line spectrophotometric analysis system: Kinetic and equilibrium study, Global Nest Journal, 13, 246-254.

Chan S.H.S., Wu T.Y., Juan J.C. and Teh C.Y. (2011), Recent developments of metal oxide semiconductors as photocatalysts in advanced oxidation processes (AOPs) for treatment of dye waste-water, Journal of Chemical Technology \& Biotechnology, 86, 1130-1158.

Chatzisymeon E., Xekoukoulotakis N.P., Coz A., Kalogerakis N. and Mantzavinos D. (2006), Electrochemical treatment of textile dyes and dyehouse effluents, Journal of Hazardous Materials, 137, 998-1007.

Frontistis Z., Daskalaki V.M., Katsaounis A., Poulios I. and Mantzavinos D. (2011), Electrochemical enhancement of solar photocatalysis: Degradation of endocrine disruptor bisphenol-A on $\mathrm{Ti} / \mathrm{TiO}_{2}$ films, Water Research, 45, 2996-3004.

Gümüş D. and Akbal F. (2011), Photocatalytic degradation of textile dye and wastewater, Water Air \& Soil Pollution, 216, 117-124.

Khataee A.R., Pons M.N. and Zahraa O. (2010), Photocatalytic decolorisation and mineralisation of orange dyes on immobilised titanium dioxide nanoparticles, Water Science \& Technology, 62, 11121120.

Konstantinou I.K. and Albanis T.A. (2004), $\mathrm{TiO}_{2}$-assisted photocatalytic degradation of azo dyes in aqueous solution: Kinetic and mechanistic investigations: A review, Applied Catalysis B: Environmental, 49, 1-14.

Li X. Z. and Zhang M. (1996), Decolorization and biodegradability of dyeing wastewater treated by a $\mathrm{TiO}_{2}-$ sensitized photo-oxidation process, Water Science \& Technology, 34, 49-55.

Muruganandham M., Sobana N. and Swaminathan M. (2006), Solar assisted photocatalytic and photochemical degradation of Reactive Black 5, Journal of Hazardous Materials, 137, 1371-1376.

Orozco S.L., Arancibia-Bulnes C.A., and Suárez-Parra R. (2009) Radiation absorption and degradation of an azo dye in a hybrid photocatalytic reactor, Chemical Engineering Science, 64, 2173-2185.

Pekakis P.A., Xekoukoulotakis N.P. and Mantzavinos D. (2006), Treatment of textile dyehouse wastewater by $\mathrm{TiO}_{2}$ photocatalysis, Water Research, 40, 1276-1286.

Poulios I. and Tsachpinis I. (1999), Photodegradation of the textile dye Reactive Black 5 in the presence of semiconducting oxides, Journal of Chemical Technology \& Biotechnology, 74, 349-357.

Poulios I. and Kyriacou G. (2002), Photocatalytic degradation of p-coumaric acid over $\mathrm{TiO}_{2}$ suspensions, Environmental Technology, 23, 179-187.

Rauf M.A. and Salman S.A. (2009), Fundamental principles and application of heterogeneous photocatalytic degradation of dyes in solution, Chemical Engineering Journal, 151, 10-18.

Rupa A.V., Vaithiyanathan R. and Sivakumar T. (2011), Noble metal modified titania catalysts in the degradation of Reactive Black 5: a kinetic approach, Water Science \& Technology, 64, 1040-1045.

Saltabas O., Teker M. and Konuk Z. (2012), Biosorption of cationic dyes from aqueous solution by water hyacinth roots, Global Nest Journal, 14, 24-31.

Silva C.G. and Faria J.L. (2003), Photochemical and photocatalytic degradation of an azo dye in aqueous solution by UV irradiation, Journal of Photochemistry and Photobiology A: Chemistry, 155, 133-143.

Sousa, J., Freitas, O.M. and Figueiredo, S.A. (2012), Basic dyestuffs removal from textile effluents using feathers: Equilibrium, kinetic and column studies, Global Nest Journal, 14, 100-107. 
Soutsas K., Karayannis V., Poulios I., Riga A., Ntampegliotis K., Spiliotis X. and Papapolymerou G. (2010), Decolorization and degradation of reactive azo dyes via heterogeneous photocatalytic processes, Desalination, 250, 345-350.

Wang K.S., Chen H.Y., Huang L.C., Su Y.C. and Chang S.H. (2008), Degradation of Reactive Black 5 using combined electrochemical degradation-solar-light/immobilized $\mathrm{TiO}_{2}$ film process and toxicity evaluation, Chemosphere, 72, 299-305. 